\title{
Enhancing business students' skills through a cross-curricular activity
}

Gil-Doménech, Dolors ${ }^{\text {a }}$ Berbegal-Mirabent, Jasmina ${ }^{a}$ and Borsot, Gabriel F. ${ }^{\text {a }}$

${ }^{a}$ Department of Economy and Business Organization, Universitat Internacional de Catalunya, Spain.

\begin{abstract}
This paper describes the experience of a cross-curricular activity that combines mathematical knowledge with several soft skills, namely the use of new technologies, teamwork and critical thinking. Two different subjects are involved, Mathematics 2 and Information Systems, both part of the Bachelor's Degree in Business and Administration, taught at Universitat Internacional de Catalunya. 42 students participated in this pilot activity during the second semester of the academic year 2015/2016.

Results indicate that students considered the activity useful and that it helped improve their knowledge on information systems and the fundamental concepts covered in Mathematics. Data gathered also reveal that students positively valued the idea of applying concepts of one subject into other subjects. As for the development of soft skills, students converge in that the activity helped them developing interpersonal skills and being more critical with one's work.
\end{abstract}

Keywords: cross-curricular activities; hard skills; new technologies; peerassessment; teamwork. 


\section{Introduction}

Higher education institutions (HEIs) are increasingly required to infuse an interdisciplinary approach among the courses and subjects taught. This call emerges from the need of boosting cooperation, learning, and research between the different disciplinary frontiers that have traditionally fragmented the university. In response to this demand, HEIs are immersed in a re-definitional process, adapting their programs in order to trigger integration and interdisciplinarity. Some examples include the creation of large-scale research projects, undergraduate training courses, and innovative graduate curricula (Holley, 2009).

It is widely acknowledged that universities should not only concentrate in fostering hard skills (i.e., knowledge regarding the discipline or profession), but also allow students develop a lifelong learning attitude with the acquisition of soft skills, which are transferrable to other fields (Badcock, Pattison, \& Harris, 2010; Kember, 2009). The ability to cooperate, communicate or solve problems exemplify these competences. Active learning methodologies are particularly appropriate for infusing such skills. They consist of involving students in the learning process making them participate in activities that improve their performance during and after the course (Bell \& Kozlowski, 2008; Prince, 2004).

In this context, the present study reports the experience of a cross-curricular activity designed to enhance students' hard and soft skills. Students are required to apply their mathematical knowledge (hard skills) in an IT subject, where they learn advanced features of the Excel work package. While performing this activity students develop several soft skills: teamwork, use of new technologies, and critical thinking (this latter through peer assessment). The underlying rationale behind this activity lies in bringing together two different subjects taught in the first course of the Bachelor's Degree Program in Business Administration at the Universitat Internacional de Catalunya (Barcelona, Spain). 


\section{Description of the activity}

\subsection{Sample}

The sample comprises 42 students from the 45 enrolled in the subject Information Systems. The activity was compulsory and was developed during the second semester of the academic year 2015/2016, after completing Module 1 in the course on Mathematics 2. Initially, students were divided in 15 teams of 3 students, but only 14 teams presented the task. In order to promote cooperation and ensure a shared level of mathematical and technological knowledge between the different teams, students were grouped according to their average grades (continuous evaluation and exams) in Information Systems and Mathematics 1 and 2.

\subsection{Description}

The activity was developed using an online platform (Moodle) as a support. This way, the instructions, team members, delivery of the tasks, peer assessments, and final grades were posted on the Moodle of the Information Systems course. Each team had a different exercise to solve (different statement based on the same concepts).

The activity had two parts (see Figure 1 and 2), and consisted on using Excel for:

1. Representing a 3D graph of a function of two variables.

2. Representing a 2D graph of the given function. The graph shows the level curve of the function that corresponds to a value of $\mathrm{z}$ specified in a cell of the Excel sheet.

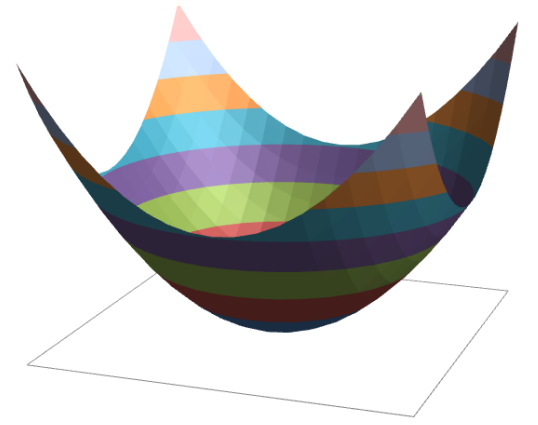

Figure 1. 3D graph of a function of two variables in Excel. 

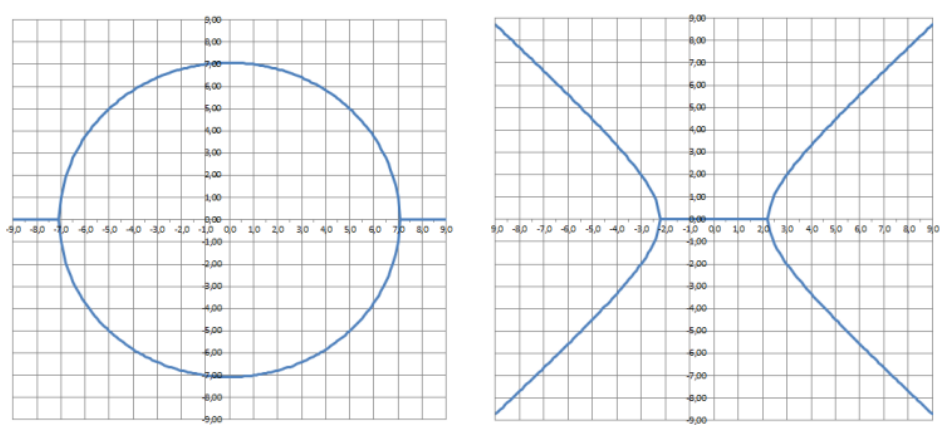

Figure 2. 2D graphs of a function of two variables in Excel (level curves for different values of z).

\subsection{Assessment}

The activity had a $15 \%$ weight in the Information Systems final grade. The exercise was both evaluated by the instructor and by other students (peer assessment). Each team was thus required to evaluate two different teams. Specifically, the final grade in the activity was composed by three grades:

1. Grade given by the lecturer.

2. Grades given by the other two teams.

3. The accuracy with which the team evaluates the two teams assigned. This grade was calculated based on the difference between the grade given by the lecturer and the grade assigned to the other teams.

Both the lecturer's evaluation and the peer assessment were based on the rubric shown in Table 1 . The activity statement and the rubric were given at the beginning of the activity so that students exactly knew how they were going to be evaluated before starting. 
Table 1. Rubric for the evaluation of the activity.

\begin{tabular}{cc}
\hline \multicolumn{1}{c}{ Concept } & Weight \\
\hline 3D function & $40 \%$ \\
Data table & $20 \%$ \\
Rightness of the calculation & $10 \%$ \\
Choice of the data range and the interval & $10 \%$ \\
3D graph & $20 \%$ \\
Clarity in the representation & $15 \%$ \\
Choice of the point of view & $5 \%$ \\
Level curves $\quad 60 \%$ & $15 \%$ \\
Cell to choose the value of $z$ & $5 \%$ \\
Clarity and visibility & $10 \%$ \\
Error message if the choice of $z$ is outside the range & $25 \%$ \\
Data table & $5 \%$ \\
Choice of the number of series required & $10 \%$ \\
Choice of the data range and the interval & $10 \%$ \\
Error management and data outside the domain & $20 \%$ \\
Graph of the level curves & $10 \%$ \\
Clarity in the representation & $10 \%$ \\
Redrawn without losing proportions & $100 \%$ \\
\hline TOTAL &
\end{tabular}

The acquisition of both soft and hard skills pursued with the activity was measured using a specific questionnaire.

The students' acquisition of mathematical knowledge was tested by a series of questionnaires. After finishing Module 1, students were asked to resolve a test in an individual fashion about the concepts that they will later apply in the activity. The instructor collects and corrects all the tests but no feedback was provided. Next, students completed the activity. After, they answered again the same test, but this time they received feedback (from both tests). Because students were given the opportunity to go beyond the theoretical concepts by performing the activity in the Information Systems class, the grades obtained in the second test were expected to be higher. 


\section{Results}

Figure 3 graphically illustrates the grades from the lecturer (in blue) and from other teams (in red and in green). From this figure, it can be inferred that except for groups E, K, L and $\mathrm{N}$, evaluations were quite homogeneous. Particularly, the graph suggests that in the aforementioned cases students tended to be more critical with others' work than the lecturer was. Note that teams $\mathrm{H}$ and $\mathrm{K}$ were only evaluated by one group as the team responsible for evaluating them (team $\mathrm{O}$ ) did not deliver their activity.

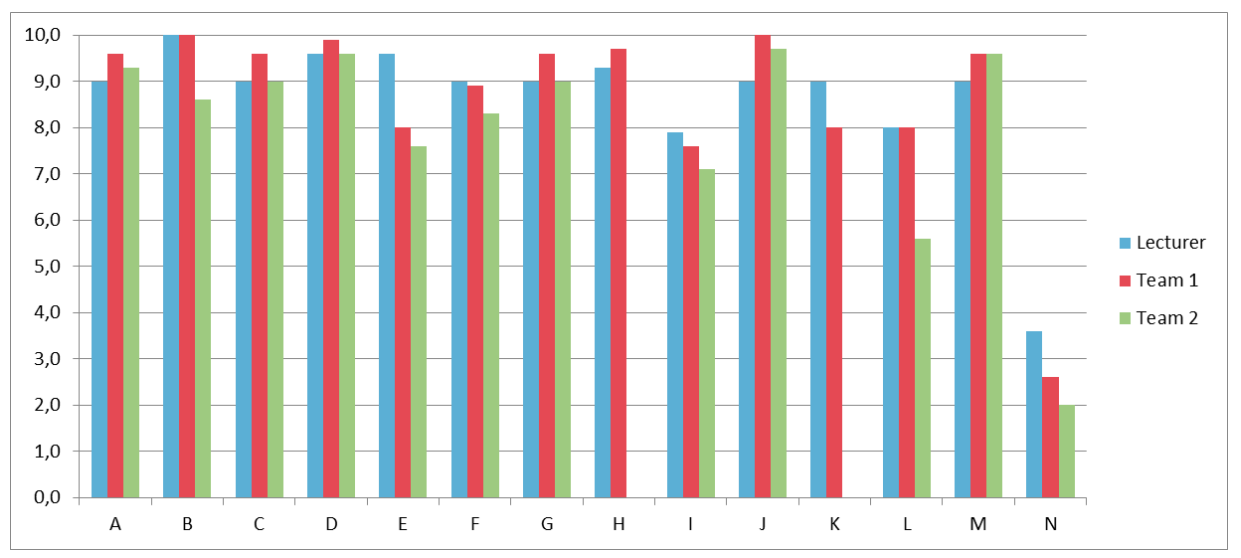

Figure 3. Lecturer's evaluation and peer assessments.

Aiming to examine whether all team members really took action in the activity, students had to answer an anonymous questionnaire indicating in a scale from 1 to 5 their own level of involvement as well as that of the students working in their team. Table 2 displays the main results. Given that the average evaluations were fairly high, it can be concluded that all team members were on an equal footing with one another.

Table 2. Team member involvement in the activity in Information Systems (scale from 1 to 5)

\begin{tabular}{ccccccccccccccc}
\hline Team & A & B & C & D & E & F & G & H & I & J & K & L & M & N \\
\hline $\begin{array}{c}\text { Average } \\
\text { evaluation }\end{array}$ & 3.83 & 3.75 & 3.67 & 2.75 & 3.50 & 4.25 & 5.00 & 2.75 & 3.83 & 4.17 & 4.00 & 4.83 & 4.00 & 2.50 \\
$\begin{array}{c}\text { Standard } \\
\text { deviation }\end{array}$ & 1.60 & 1.90 & 1.75 & 0.82 & 1.51 & 0.84 & 0.00 & 1.97 & 1.83 & 1.17 & 1.17 & 0.41 & 1.22 & 1.29 \\
\hline
\end{tabular}

As a way to compare the usefulness of the activity, when students had completed Module 2 they had to answer a test (similar structure as in Module 1 but covering the content of Module 2). A couple of weeks later, they were asked to repeat the same test of Module 2. Little variation of grades was expected between these two latter tests as no cross-curricular activity was implemented for this module. Results in Table 3 confirmed our initial intuition. 
Table 3. Grades associated to tests in Mathematics 2

\begin{tabular}{cccc}
\hline & Before & After & Improvement \\
\hline With activity & 4.84 & 5.38 & $11.16 \%$ \\
Without activity & 4.29 & 4.29 & $0.00 \%$ \\
\hline
\end{tabular}

Finally, Figure 4 shows students' opinions regarding the learning strategy, the methodology used, and the acquisition of soft and hard skills as a consequence of this activity.

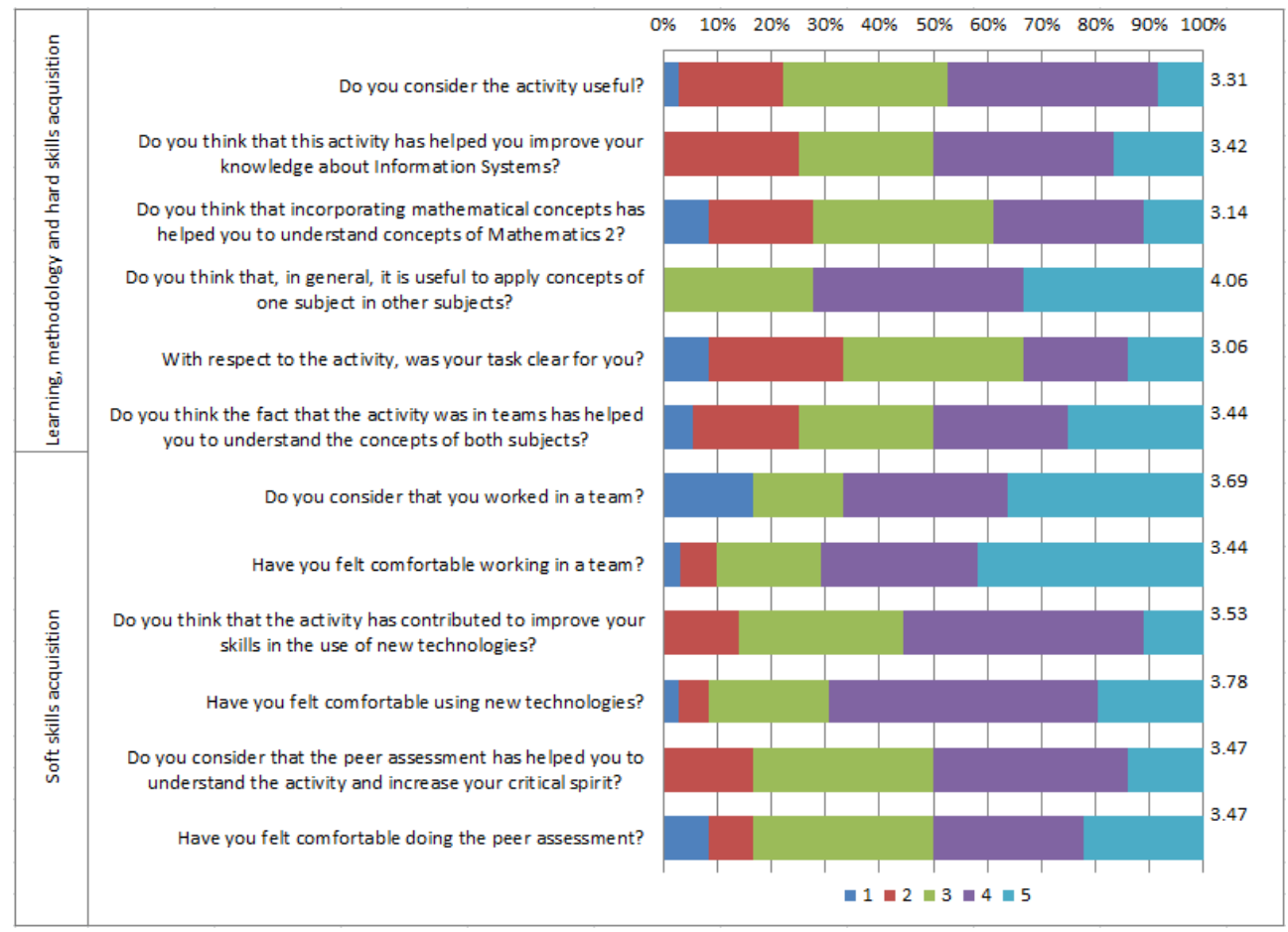

Figure 4. Results obtained from students' feedback in Information Systems (numbers in the right hand of the figure indicate the average grade in a scale from 1 to 5 ).

The item that was most highly ranked (4.06 out of 5) was the usefulness of applying concepts of one subject to another one, reinforcing the adequacy of cross-curricular activities as the one presented here. It also remarkable that, for this item, all evaluations reached a minimum score of 3 . This result further corroborates the suitability of adopting such an approach. Regarding the development of soft skills, both teamwork and the use of new technologies were highly valued (3.69 and 3.78, respectively). On the contrary, students considered that the activity could be improved in terms of the clarity of the task to be done (3.06). Undoubtedly, this feedback will be very helpful for future editions in improving the way instructions are communicated to students. 


\section{Discussion and conclusion}

Cross-curricular approaches to teaching and learning have been recently disrupted the educational landscape. This pedagogy is characterized by a synthesis of, knowledge, skills and understanding from various subject areas. Although academic literature addressing this topic is still scarce, this pedagogy is increasingly being discussed and utilized by educators.

The purpose of this paper has been to provide evidence of the usefulness of cross-curricular activities in the higher education context. More specifically, the activity described is intended to connect and combine two different subjects. That is, new learning from Mathematics and Information Systems is put together to generate a valued experience. The rationale that underpins this pedagogy spans out from the work of individual instructors to collaborative approaches.

As for the case described, the intertwining of the two disciplines selected is shown to deepen the response to a single experience. Our findings reveal that thanks to the crosscurricular activity, students' performance (in terms of the mathematical knowledge gained) substantially improved. In addition, while conducting the activity students strengthened technological skills, improved their interpersonal skills (teamwork) and learned how to critically assess others' work.

Team working is considered one of the essential skills that should be provided by universities (Ruizacárate Varela, García-García, González-García, \& Casado-Sánchez, 2013). When learning with others, students are able to learn more because of the process of achieving a shared understanding during the development of the activity (Cortez, Nussbaum, Woywood, \& Aravena, 2009). Thus, teamwork becomes a positive learning experience while it inspires genuine cooperation among students. Furthermore, our activity is complemented with a peer assessment task. As a learning instrument, assessing others boosts critical thinking and helps students learning what a high-quality work consists in (Liu \& Carless, 2006; van Zundert, Sluijsmans, \& van Merriënboer, 2010).

We hope this experience encourages other instructors to design and implement crosscurricular initiatives. Although an effective implementation of such initiatives requires an extra effort compared to the use of traditional lectures and a clear definition of the objectives to be achieved in each of the disciplines involved, we believe it promotes authenticity in teaching and learning.

This study is not free of limitations and from the feedback obtained, there is still room for improvement. Specifically, some issues that need to be fixed which constitute opportunities for future editions might include: clarifying the tasks to be done and the expected outcomes, involving more instructors in the design of the activity, adding more cross-curricular 
activities for the other modules of the course on Mathematics 2, allowing students a blank space for additional feedback.

\section{References}

Badcock, P. B. T., Pattison, P. E., \& Harris, K.-L. (2010). Developing generic skills through university study: a study of arts, science and engineering in Australia. Higher Education, 60(4), 441-458.

Bell, B. S., \& Kozlowski, S. W. J. (2008). Active learning: effects of core training design elements on self-regulatory processes, learning, and adaptability. The Journal of Applied Psychology, 93(2), 296-316.

Cortez, C., Nussbaum, M., Woywood, G., \& Aravena, R. (2009). Learning to collaborate by collaborating: a face-to-face collaborative activity for measuring and learning basics about teamwork. Journal of Computer Assisted Learning, 25(2), 126-142.

Holley, K. A. (2009). Interdisciplinary strategies as transformative change in higher education. Innovative Higher Education, 34(5), 331-344.

Kember, D. (2009). Nurturing generic capabilities through a teaching and learning environment which provides practise in their use. Higher Education, 57(1), 37-55.

Liu, N., \& Carless, D. (2006). Peer feedback: The learning element of peer assessment. Teaching in Higher Education, 11(3), 279-290. http://doi.org/10.1007/s13398-0140173-7.2

Prince, M. (2004). Does active learning work? A review of the research. Journal of Engineering Education, 93(July), 223-231.

Ruizacárate Varela, C., García-García, M. J., González-García, C., \& Casado-Sánchez, J.L. (2013). Soft skills: a comparative analysis between online and classroom teaching. 2013 International Conference on Advanced Education Technology and Management Science AETMS, 359-366.

van Zundert, M., Sluijsmans, D., \& van Merriënboer, J. (2010). Effective peer assessment processes: Research findings and future directions. Learning and Instruction, 20(4), 270-279. 